cause of the endocarditis. It is evident from the formation of the opening in the septum that the stream of blood would four luring systole from the left side to the right, and it is conceivable that the impact upon the tricuspid valve may thus have given rise to the endocarditis. It would be difficult to ascribe the arrest of development in the septum to the endocarditis and subsequent incompetence of the tricuspid valve, as that theory would entail our dating back the endocarditis to a period anterior to the third month of fostal life; and moreover, had increased pressure within the right ventricle prevented the completion of the septum, one would naturally look for the opening to be larger upon the right side than upon the left.

Manchester.

\section{SOME REMARKS ON TYPHOID FEVER MADE AT A CLINICAL DEMONSTRA- TION IN THE WARDS OF THE ROYAL BERKSHIRE HOSPITAL, READING. ${ }^{1}$}

\section{BY FRANCIS HAWKINS, M.B. EDIN.,} PHYSICIAN TO THE HOSPITAL.

The patient was a man twenty-seven years of age who had been a scavenger. When admitted to hospital on June 11th he said that he had had slight diarrhoa on the first day of the month, but continued at his work until the fifth, when he had a shivering fit, and owing to the diarrhoea increasing took to bed. When I saw the case on the eleventh day, shortly after his admission, the house physician took from my dictation the following notes: "The patient complains of frontal headache and diarrhoea. He lies on his back. The face is markedly flushed and his pupils are dilated; his tongue is beefy red, moist towards the edges, but dry at the centre. The abdomen is tumid, tympanitic over all regions, but markedly so over the colon. Two circular pink spots, slightly raised from the surface and disappearing on pressure, are seen in the left umbilical region. The spleen is enlarged upwards, the lower border not being felt; the liver is not enlarged; the heart is normal. There are a few sibilant rulles at the base of both lungs. There is no albumen in the specimen of urine examined; the temperature is $102^{\circ} \mathrm{F} . "$ Since admission there have been several successive crops of spots. The temperature has, with one exception, not been above $102^{\circ}$. The bowels, however, have been frequently and profusely active.. In addition to this, on the sixteenth day at 4.30 A.Mr. about one pint of blood, dark in colour and somewhat clotty, was passed, and a similar quantity again at 7.30 A.M. There was no sign whatever of collapse (the temperature, however, which had previously risen a few degrees, fell from 102.6 to 99.2). I wish to refer in this place parenthetically to the occurrence of typhoid ferer at various periods of life. While it is most common during the second and third decades, yet it is very prevalent during the first, but it is not by any means common before the second year of life. I have myself never met with a case in a patient under two years and a half old, but Meigs and Pepper record a case as young as one year and six months. In the cases from which my own investigations have been made not one was under two years. Henoch in 256 cases also found none under two years. This fever may in exceptional instances be met with at an advanced age. One case recorder within my knowledge occurred between the ages of seventy and eighty - the exact age was seventy-six. The most advanced age of which $I$ find an account was a case mentioned by Griesinger as having been observed by Hammernyk when the patient was ninety years of age.

[Dr. Hawkins here quoted statistics showing that typhoid fever is most prevalent during the months of August, September, October, November, December, and least prevalent during April, May, June, and July. He proceeded :]

The eruption in this case appeared first on the day of admission. I have it from the previous medical attendant that none was to be seen on the day before admission, but on

I I must publicly tender my thanks to the staff of the Middlesex Hospital for their kindness in having placed at my disposal the notes on cases of typhoid ferer for the past ten years, whence all my facts not otherwise stated have been drawn. the day of admission-the eleventh day of illness-two spots were seen. The typical typhoid eruption is not present in every case; it is, however, more frequently present than absent. As regards adults, it is more frequently present in the male than in the female, being seldom absent in the male. In children it is less frequently present than in the adult. In male children it is almost as frequently absent as present, but in females it is more frequently present than absent.

The date of the appearance of the eruption is worthy of notice. In this case it appeared on the eleventh day. Murchison tells us that the spots appear between the seventh and twelfth days inclusive. In an investigation made by him it was so in 39 out of 46 cases; in 4 only were the spots seen before the sixth day, and that was on the fifth; and in 3 cases the spots were not seen till the fourteenth, and in one case not till the twentieth day. Murchison, however, made no distinction between the date of appearance of the eruption in children and in adults, and as this line of inquiry seems to be of interest and importance I will give some of the results of my investigation. I find that the eruption may appear earlier in children than in adults; thus in the former (of 78 cases) the eruption appeared on the third day in 1 case and on the fourth day in 3 cases. In the latter (adults) in 69 cases the eruption did not appear in one single instance before the fifth day. In 2 cases which I have lately seen the eruption did not appear till the eighteenth day.

The situation of the eruption is almost universally on the abdomen. Among 56 cases where its distribution was particularly noted, in one case only was the eruption absent from the abdomen, and in that instance it was on the chest and back. It is, however, to be remembered that while the eruption is so constantly present on the abdomen it may appear in other parts as well. Thus it may be on the back, chest, between the thighs, on the knees, shoulders, elbows, forearm, neck, and face. It may be very profuse or very scanty. Shortly before leaving London I saw in consultation a case in which the eruption was so general and so widely distributed that the practitioner in attendance thought it of an influenza type. There are other conditions of the skin which must be mentioned, for in addition to sweating and the presence of sudamina there may be erythema, eczema (which is perhaps the least common of any one case out of 240 presenting this condition), urticaria, herpes facialis, and labialis. Abscesses also appear as alveolar, parotid, or on the hips. It must, however, be mentioned that with the exception of erythema the majority of the above-mentioned are met with as sequela. And this reminds me of one case I saw while resident physician in the Royal Infirmary at Edinburgh, in which, during convalescence, an abscess formed at the ankle joint, and the os calcis was found to be so much necrosed that the foot was amputated. Previously to the fever no sign of any such condition was present. Boils also may appear: in the experience of some they are of frequent occurrence. The eruption of measles, as also the rash of scarlet fever, may arise during the course of the disease. Desquamation of the skin apart from this cause may also be met with. It was noticed in 11 out of 240 cases, the earliest appearance being on the twentieth day and the latest the thirty-eighth. "Purpura may occur," Fagge says, "in typhoid cases with hæmorrhage from the bowels"; but in 61 cases of hæmorrhage from the bowels (representing a ten years' experience at the Middlesex Hospital) purpura did not occur in one single case. Purpura rheumatica claims two instances. One, a man aged twenty-two years, who had previously suffered from rheumatic fever and hæmoptysis, and in whom a cardiac bruit was present, had on his admission both legs from the knees downward studded with minute petechix, and on both ankles and on the dorsum of each foot large hæmorrhagic plaques. For some time the case was regarded as one of peliosis rheumatica. On the sixteenth day typical typhoid spots appeared, and on the twenty-second and twenty-fifth days crops of spots appeared "which became petechial." The other case was a man fiftytwo years of age who had petechiæ over the ankles. Both cases recovered. I call special attention to the expression "became petechial," because Murchison says: "When petechiæ occur they are not developed in the centre of the ventricular spots, but are independent." The above case was not seen by myself ; it is recorded in the published reports of the Middlesex Hospital, and was noted by such a competent observer as Dr. J. J. Pringle, who was registrar at the time. 
[Dr. Hawkins here referred further to the comparative rarity of purpura in typhoid fever. He continued :]

I now come to the condition of the bowels and the frequency of the stools. 'This is one of the difficulties with which we have most to contend. The notes of the case mentioned the presence of tympanitis over the regions of the colon, indicating distension of that part of the bowel. Now in several other cases in which I have detected this condition, which is nearly always associated with profuse cliarrhœea, extensive ulceration of the colon has been found at the necropsy. Diarrhoea is the rule in typhoid fever, constipation the exception; but it must also be remembered that there may be diarrhœa for a few days-say, the first five or six-followed for one or two weeks by the most obstinate constipation, demanding enemata for its relief. This latter condition is much more common than constipation throughout. The bowels may be moved from twice to twelve or more times in the twenty-four hours. In adclition to frequency of the stools we have here had to contend with hæmorrhage from the bowels, and this symptom demands more than passing attention. Graves was the first to teach that hæmorrhage from the bowels in typhoid fever might be a favourable symptom rather than an unfavourable-he regarded it "as a wise provision of nature which might usher in a favourable crisis, but as an occasional result it was of great danger." Tronsseau for some time held that it was a formid. able symptom and increased the danger, but after reading Graves' lectures he changed his opinion and stated "that as a symptom intestinal hrmorrhage did not possess the dangerous character imputed to it, but that it was usually of a favourable augury," Sir William Jenner writes: "Hæmorrhage from the bowels is a very grave symptom, but it is by no means necessarily fatal." And Sir William Broadbent, writing in Quain's Dictionary of Medicine, tells us that, while intestinal hæmorrhage is a symptom which causes anxiety, it is by no means necessarily fatal. Murchison regarded it as a very formidable symptom, but Habershon wrote : "It is in my experience rarely fatal." Some time ago I made an investigation relative to this important symptom with the object of finding some basis for forecasting the issue of cases associated with it. A glance at this tabular statement will show that up to the age of twenty more cases recover than die, and that between twenty and twenty-five nearly as many cases die as recover, but that between twenty-five and thirty more recover than die. After the age of thirty more die than recover. We have, therefore, so far as age is concerned, some data for making a prognosis, for, speaking

Tabular Statement of Ages at which Hemorrhage from the Bowels occurred in Typhoid Hever, showing the Ages of Non-fatal and Fatal Cases.

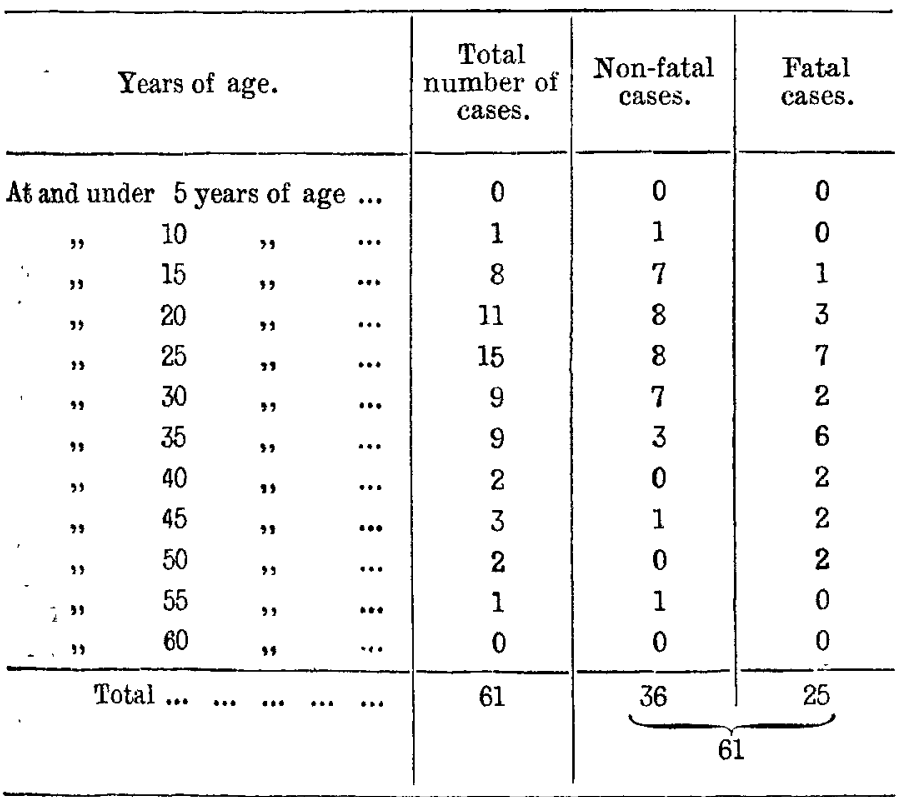

broadly, one may say that up to the age of twenty the symptom is less indicative of danger than it is after that age. In non-fatal cases hæmorrhage usually occurs but once - that is to say, only at one period is blood seen in the stools, and it may vary from a few streaks to one pint. A single hamorrhage occurred in seventeen out of, twenty-eight nonfatal cases. Hæmorrhages in fatal cases are more frequently recurring. Of twenty-four fatal cases there were but three instances of a "single occurrence"; but when these recurrent hamorrhages are fatal we have no data to guicle nis, for in both fatal ancl non-fatal cases the recurrences may be equal in number aud frequency. Hxmorrhage iskecinter with perforation is always fatal, and is more frefuently recurrent. When a homorrhage of the single type has occurred comparatively early in the course of the fever, and for a while the patient seems to have passed the danger point, hamorrhage of the recurrent type may occur later, from which the patient dies. With regard to the time of the occurrence of the hæmorrhage there is practically no difference. I must lay stress upon this, for many persons think that hamorrhage early in the course of the fever is not fatal. So far as my own observations go, data of this kinc are not reliable, neither cloes the quantity of the blood passed help much in guiding our judgment, for in non-tatal as well as in fatal cases the quantity may be large or small, and we must further remember that, while the quantity passed by the bowel may be small, a large quantity may remain in the intestine.

I must be brief as to treatment. The patient was at first put on a purely milk diet, but shortly afterwards he vorniterl curdled milk, and in the stools there was also undigested milk. 'Ihis form of diet was therefore stopped, broths being given, and during the time of the hrmorrbage raw meat juice. Milk, if a patient can digest it, is by far the best diet, yet it should not be unduly pushed when, as in this case, there is evidence that it does not agrec. In fact, it may do harm not only by causing sickness, but also by increasing the diarrhcea. For checking activity of the bowels I prescribed bismuth and componnd powder of ipecacuanha. However, I am bound to admit it has not answered my expectations. Starch and opium enematit were then ordered, but as this did not check the activity of the bowels I ordered opinm by the mouth in addition; by this combination I succeeded in diminishing the frequency of the stools. During the attack of hæmorrhage, in addition to slightly increasing the dose of opium an icebag was placed over the abdomen, and more especially over the right iliac region, suspended from a cradle so as to touch the abdomen lightly and to be removed at intervals. The hæmorrhage eventually ceased. In some instances the cold pack is of great use, but in this case the temperature had never been higher than $102^{\circ}$ and therefore in my opinion did not require any special treatment. Stimulants were not administered at first, but a few days after admission the pulse became not only irregular, but also intermittent, and brandy was therefore given. So soon 2 s the desired result was obtained it was stopped, but lasterly it has been given regularly because there are indications of cardiac failure.

Reading.

\section{A CASE OF 'TETANUS TREATED WITH TETANO-ANTITOXIN, AND A REVIEW OF THIRTY-EIGHT OTHERS.}

By F. HERBERT MARSON, M.D. DURH., F.R.C.S. ENG., LATE HOUSE SURGEON TO THE STAFFORDSHIRE GENERAL INFIRMARY.

I HAve to thank Mr. Weston, senior surgeon to the institution, for permission to publish the following case.

On Nov. 10th, 1894, a man aged twenty-eight was admitted to the Staffordshire General Infirmary with a compound fracture of the first phalanx of the left thumb, arisl complaining of slight stiffness of the masseter muscles. The injury to the thumb, which was slight, had been received ten days previously and had been medically treated from the first. The stiffness of the jaws had only commenced on the morning of his admission. The patient was a strong, healthy man. His pulse and temperature were normal. There was slight stiffness of the jaws. The wound, which was small, did not look heal thy. He was put on five grains of quinine every four hours ancl a quarter of a grain of extract of physostigmine hyporlermically every six hours. On the 13th his condition romainert yractically the same; the pulse was normal and the temperature never excected $99.4^{\circ}$ F. Ho could open his mouth about half an inch. As the wound still looked unhealthy tho thumb was removerl. On the 14 th, on account of the cardian 